\title{
A EXPERIÊNCIA DO DIEESE EM PESQUISA E CONHECIMENTO
}

\author{
Sérgio E. A. Mendonça
}

\begin{abstract}
Resumo: O texto situa o nascimento do Dieese com o objetivo singular de realizar pesquisas e estudos a partir da ótica da classe trabalhadora. O Dieese nasce para tentar produzir conhecimento em bases científicas, visando apoiar a disputa da classe trabalhadora pela distribuição de renda nacional. Relaciona os momentos de transformação da sociedade brasileira às principais pesquisas e atividades desenvolvidas pela instituição. Assim, os estudos e as pesquisas (inflação, custo de vida, cesta básica, salário mínimo, política salarial, emprego e desemprego, educação) surgem "datados" historicamente na vida do Departamento e estão ligados aos desafios daquele momento para os trabalhadores.
\end{abstract}

Palavras-chave:

\begin{abstract}
This article describes the birth of the institution Dieese, created with the sole purpose of carrying out research from the perspective of the working class. Dieese seeks to produce scientifically based knowledge in support of workers' demands for more equitable income distribution. This article links historical turning points affecting Brazilian society to the institution's major research projects and activities. Thus, the various studies (inflation, cost of living, the staple goods index, the minimum wage, wage policy, employment/ unemployment and education) appear chronologically within the history of Dieese and reflect the challenges facing the working class at each particular moment.

Key words: labor statistics; unionism and negotiation; social research.
\end{abstract}

$\mathrm{D}$ e acordo com o Dicionário Aurélio, "idéias" são um conjunto de pensamentos ou concepções de um indivíduo ou de um grupo social em qualquer domínio; teoria; doutrina; filosofia; ponto de vista, opinião.

Na legítima disputa por espaço, os cientistas desejam que suas idéias ou contribuições para a ciência sejam reconhecidas e utilizadas para a explicação dos fenômenos que estudam, contrapondo-as a outras idéias no campo do debate, em que as diferentes opiniões expressam-se em diversas respostas às mesmas questões.

No processo de construção destas respostas, tornamse as escolas de pensamento, ou seja, as redes compostas por membros cientistas, que desempenham papéis diferenciados na defesa das idéias. Entre eles, há os teóricos, que estão voltados para a elaboração e o desenvolvimento dos argumentos a serem utilizados, e aqueles que estão envolvidos diretamente na luta contra os adversários na disputa por adeptos - fonte vital de recursos para a continuidade do debate e posterior tentativa de vitória (Earp, 1996).

É nesse espaço, do embate de idéias, que nasce o Dieese - Departamento Intersindical de Estatística e Estudos
Sócio-Econômicos, ${ }^{1}$ fruto da necessidade da classe trabalhadora brasileira de se instrumentalizar na disputa pela distribuição da renda nacional.

O Dieese originou-se, portanto, do conflito de classes e se desenvolve para a defesa dos interesses dos trabalhadores no campo das idéias.

De acordo com seu estatuto do final dos anos 70, "O Departamento tem por finalidade o estudo social, econômico e jurídico das condições de trabalho das categorias profissionais e da situação das empresas, bem como o levantamento estatístico destinado à apuração de dados relativos a custo, nível e padrão de vida dos trabalhadores e o regime de redistribuição do trabalho assalariado".

Segundo Chaia (1992:14), "a singularidade do Dieese transparece, de imediato, em seu primeiro 'Boletim', publicado em maio de 1960. Nessa publicação, o Departamento declara que é seu objetivo 'realizar estudos e pesquisas sobre problemas da classe trabalhadora. Representa, pois, uma inovação dentro do movimento sindical brasileiro, no sentido de uma tomada de consciência de que a situação do trabalhador e as condições de trabalho achamse enquadradas num conjunto de fatores nacionais, e de que o conhecimento de uma e outras deve ser feito medi- 
ante a utilização de métodos modernos elaborados pelas ciências sociais"”.

Assim, discorrer sobre pesquisa e produção do conhecimento no Dieese é extremamente gratificante e colocase como um grande desafio. Gratificante por ser esta uma instituição que, ao longo desses quase 50 anos de história, vem buscando desempenhar um papel relevante na luta dos trabalhadores pela melhoria das condições de vida e trabalho no Brasil. E um grande desafio pela experiência - até onde sabemos - única no mundo, que procurou e procura conjugar produção de conhecimento pela perspectiva da classe trabalhadora através da utilização de instrumental científico e voltada para a ação sindical.

No decorrer deste texto, procurar-se-á abordar o caráter do Dieese e contextualizar sua produção a partir de sua concepção e história.

\section{ANTECEDENTES HISTÓRICOS}

A industrialização brasileira ganhou impulso após a década de 30, trazendo consigo enormes transformações sociais. A velocidade de instalação das indústrias nos centros urbanos e o vigoroso deslocamento populacional do interior para este e entre as regiões contribuíram para a formação de um mercado de trabalho extremamente heterogêneo.

Entre 1945 e 1955, com o fim da ditadura do Estado Novo, a condução econômica do país oscilou entre o liberalismo e o nacional desenvolvimentismo, tendo este prevalecido na orientação dos governos de então.

Neste período, o movimento sindical organizou-se dentro de uma estrutura dual em que, para além do modelo vertical e controlado pelo Estado determinado pela legislação, vez por outra, eram empreendidas iniciativas horizontais através de estruturas paralelas. Entre estas iniciativas destacaram-se o PUI - Pacto de Unidade Intersindical, o PUA - Pacto de Unidade e Ação e o CGT - Comando Geral dos Trabalhadores. Da experiência do PUI, criaram-se as condições para o surgimento do Dieese (Chaia, 1992: cap. 2-3).

\section{A CRIAÇÃO DO DIEESE: OS PRIMEIROS ANOS}

O Dieese, que de acordo com seu estatuto "congrega e é constituído por entidades sindicais e associações profissionais de trabalhadores e empregados do Brasil", foi criado na esteira dessas iniciativas e seu objetivo foi o de quebrar o monopólio patronal das informações.
Na primeira metade da década de 50, houve em São Paulo um recrudescimento da atividade grevista e a conjuntura econômica mesclava crescimento e inflação. Nas negociações coletivas de trabalho, os sindicatos desconfiavam dos números apresentados pelo governo no que se referia aos preços. Apenas como detalhe: o responsável pelo cálculo do índice de custo de vida patrocinado pela Prefeitura de São Paulo era também assessor econômico da Fiesp. A esta desconfiança, acrescia-se o discurso patronal desqualificando as reivindicações dos trabalhadores pelo desconhecimento técnico destes em relação ao custo de vida.

O surgimento do Dieese se deu pela necessidade de os trabalhadores contraporem suas idéias às idéias dos patrões. Com este objetivo, o movimento sindical concebeu o Dieese como órgão técnico do movimento sindical e, essencialmente, unitário.

Como toda iniciativa científica, a tentativa de apreender a realidade segundo um determinado propósito e ponto de vista necessita de elaboração. Os primeiros anos do Dieese foram o de construção e implantação do ICV - Índice de Custo de Vida e de teste para sua sobrevivência como proposta.

Nesse período, portanto, o Dieese orientou-se para o desenvolvimento de um instrumental que permitisse a construção de um discurso contra a primeira idéia a ser combatida: "trabalhador não sabe fazer conta! Trabalhador não entende de inflação!", de forma a impedir a desqualificação do movimento sindical para a defesa de seus próprios interesses.

\section{O PERÍODO DA REORGANIZAÇÃO E DA RESISTÊNCIA}

Sendo iniciativa não só sindical, mas também científica, a criação, a organização e a gestão do Dieese contaram com a participação de sindicalistas e de cientistas. $\mathrm{Na}$ amarração do objetivo político de se contrapor ao discurso patronal com a solidez de um discurso científico elaborado sob a ótica dos trabalhadores, o espaço aberto pelo Dieese agregou apoiadores no meio sindical e colaboradores na área acadêmica, em que foram recrutados seus quadros técnicos. Apesar das dificuldades, o Dieese firmou-se por quase nove anos, sendo obrigado a hibernar por meses em 1964, ano do golpe militar que, entre outras coisas, desarticulou o movimento sindical.

Para os anos seguintes - e praticamente até a década de 90 -, o grande objeto de estudo para o Dieese foi a 
inflação, suas conseqüências para a classe trabalhadora e as políticas governamentais para combatê-la.

Após o golpe de 1964, não bastava medir a variação dos preços corretamente; era necessário adentrar o mundo dos números para tornar inteligíveis intrincadas fórmulas matemáticas que o ministro de então julgava oportunas para substituir todo o complicado jogo de forças presente nas negociações salariais entre sindicatos e patrões (Simonsen e Campos, 1975:112).

Aqui o discurso do governo e dos patrões poderia resumir-se em: "reajuste de salário gera inflação". Daí derivou-se toda uma série de políticas econômicas que, independentemente de sua consistência, utilizavam os salários como variável de ajuste. Com isto, o conjunto das medidas econômicas quase sempre incluía um artifício para reduzir os parâmetros de correção de preços no momento de seu repasse aos salários.

Ao tornar mais complexas as fórmulas de correção dos salários, além dos objetivos imediatos e concretos de arrochá-los e de enfraquecer as negociações coletivas, o governo visava tirar do domínio dos trabalhadores o controle sobre sua própria remuneração, dado que seu tratamento passava a ocorrer na órbita do Estado e por mecanismos inacessíveis. Essas medidas tentaram impedir que os trabalhadores pudessem aferir a real perda de seu poder aquisitivo e a brutal transferência de renda daí decorrente.

Esse contexto levou à sofisticação da argumentação dos trabalhadores, pois não bastava mais provar que havia inflação; era preciso mostrar que o seu repasse aos salários, determinado pelas políticas salariais, era apenas parcial e, portanto, não poderia ser responsabilizado como causa principal do processo inflacionário.

O Dieese, ao longo da segunda metade da década de 60 e também nos anos 70, empreendeu vigorosos esforços para desvendar os instrumentos de política salarial, de forma a torná-los claros e inteligíveis ao movimento sindical e para dar substância aos argumentos dos trabalhadores na defesa de seu poder de compra. Entre os principais trabalhos elaborados nesse período, destacam-se a segunda Pesquisa de Orçamento Familiar-POF, concluída no início dos anos 70 (Dieese, 1974), o estudo 10 anos de política salarial (Dieese, 1975) e a denúncia da manipulação dos índices de 1973.

Cabe, aqui, um aprofundamento desses três episódios, que foram especialmente marcantes na história do Dieese.

A segunda Pesquisa de Orçamento Familiar teve um grande avanço metodológico em relação à primeira, representando um salto qualitativo na produção do Dieese.
Em primeiro lugar, foi ampliada a população pesquisada, que se estendeu a quase toda a cidade de São Paulo e a assalariados em geral. Na primeira POF, haviam sido pesquisados apenas os associados dos sindicatos filiados ao Dieese que apresentassem um perfil "padrão" pré-definido em função do rendimento, moradia alugada e tamanho da família. Além disso, houve um aumento significativo da amostra da pesquisa.

Estes avanços demonstram a capacidade da instituição em criar instrumental para captar a realidade da classe trabalhadora e adequá-lo às mudanças que se impõem. Neste caso, criou-se um instrumental capaz de averiguar o novo padrão de orçamento da família trabalhadora, dada a mudança no perfil do assalariamento entre os anos 60 e 70, no Brasil.

Também a publicação 10 anos de política salarial representa um marco para a história do Dieese. Nela, foram destrinchados os mecanismos de arrocho salarial utilizados pelo governo e mensuradas as perdas dele decorrentes, o que a tornou uma importante referência para a discussão salarial no Brasil.

Entretanto, é a manipulação do índice oficial de inflação, em 1973, que dá ao Dieese destaque na sociedade brasileira. A denúncia, publicada por um jornal de São Paulo em 1977, contrapõe o dado divulgado pelo governo federal (utilizado para os cálculos de reajuste salarial) ao índice calculado pelo Dieese. Posteriormente, há o reconhecimento público da manipulação, o que confirma que o índice do Dieese é o que traduzia o verdadeiro comportamento da inflação daquele ano.

É a partir daí que o Dieese projeta-se no cenário nacional e passa a ser reconhecido pela credibilidade, sua principal característica até os dias atuais.

Assim, no período compreendido entre meados dos anos 60 e final da década de 70, o Dieese investiu na construção de um discurso técnico que serviu aos sindicatos como contraponto à fala do governo e dos empresários e, a partir disso, consolidou sua atuação junto ao movimento sindical, além de adquirir reconhecimento na sociedade civil.

\section{A REARTICULAÇÃO - A RETOMADA DAS NEGOCIAÇÕES E OS PACOTES ECONÔMICOS}

Já no final dos anos 70 e durante a década de 80 , o tratamento dado à inflação pelos governos revestiu-se de seguidas doses de sofisticação. No âmbito técnico, ao debate da correção dos salários foi acrescida a questão da produtividade como limite "técnico" aos aumentos reais - o que levou o movimento sindical a discutir e questionar o acesso às infor- 
mações das empresas para a aferição desse indicador - e introduzidos inúmeros e cada vez mais complexos mecanismos para cálculo dos reajustes de salários (gatilhos, redutores, resíduos, expurgos, médias, novos índices, etc.).

No âmbito político, prevaleceu a prática dos pacotes econômicos, que, além de complicadas fórmulas salariais, adquiriram ainda um caráter salvacionista, de tal maneira que o questionamento dos pacotes - e por extensão das políticas salariais neles contidas - era considerado, pelos governos, um ato contrário aos interesses do país.

Nesta época, a cada pacote econômico, o Dieese realizava um estudo explicativo e analítico acerca dos efeitos sobre a classe trabalhadora das alterações provocadas pela política econômica então implantada.

Foi também a partir do final dos anos 70 e em todo o decorrer da década de 80 , que novos desafios passaram a se colocar para os trabalhadores na relação capital-trabalho, dadas as mudanças da economia em nível mundial e o avanço significativo do movimento sindical e das negociações coletivas no Brasil.

Nesse contexto, o Dieese ampliou seu campo de análise, passando a enfatizar outras dimensões do mundo do trabalho, como emprego e desemprego, processo de trabalho, automação, formação profissional, terceirização e sistema de relações de trabalho.

Além disso, o Departamento passou a realizar, sistematicamente, o acompanhamento das greves e das convenções e acordos coletivos de trabalho, importantes indicadores sindicais, que permitem a avaliação da organização e expectativas dos trabalhadores, bem como captar o estágio, a evolução e a tendência das relações entre capital e trabalho.

Assim, o esboço do Dieese como "um grande instituto (...) em questões de trabalho (...) que fosse um depositário de todo movimento sindical, em termos de artigos sobre greves, estudos sobre padrão de vida, levantamentos salariais, lucros de empresas, análises de grupos econômicos (...) um instituto do 'Lavoro', do Trabalho, onde, também, todo cientista social interessado nas questões trabalhistas pudesse encontrar as informações que quisesse num arquivo especializado" (Chaia, 1992:63) torna-se realidade.

Também nos anos 80 houve uma expansão significativa do Dieese, tanto em nível regional - com a criação de vários Escritórios que acabaram por consolidar-se em 15 unidades da federação, além do Distrito Federal - quanto em âmbito setorial, com a abertura de diversas subseções; ou seja, com a contratação de técnicos para assessoria permanente a entidades sindicais de várias categorias ligadas ao Dieese.
Essa expansão abriu possibilidades de reorganização da estrutura interna do Dieese, de forma a aprofundar e especializar a análise desenvolvida pela instituição, não mais apenas em caráter regional, mas buscando reafirmar uma visão abrangente, plural e nacional.

\section{UMA OUTRA DIMENSÃO: A EDUCAÇÃO SINDICAL}

Convém lembrar que a partir do final dos anos 70, o Dieese intensificou também as atividades de educação sindical em temas relacionados à negociação coletiva de trabalho e à produção técnica desenvolvida pela instituição.

A demanda vinda dos dirigentes sindicais e a opção que o Departamento fez por trabalhar de forma sistemática a dimensão educativa decorrem da natureza do Dieese. A eficácia em produzir conhecimento com o objetivo de subsidiar a ação do movimento sindical está diretamente associada à apropriação e à recriação, por parte dos dirigentes sindicais, do conhecimento produzido, conferindo sentido ao saber acumulado por eles ao longo da vida e possibilitando a troca de significados entre pessoas e grupos.

Assim, a partir da prática da negociação coletiva, o Dieese passou a desenvolver atividades (seminários, cursos, oficinas, intercâmbios, palestras) e programas (um conjunto articulado de atividades) que tratam de estudar o objeto da negociação (as questões econômicas, sociais e políticas que compõem a agenda de uma negociação), o ambiente em que ocorre a negociação (os marcos institucionais, o sistema de relações de trabalho, a conjuntura socioeconômica, etc.) e a estratégia e tática nas negociações, além da conduta e comportamento dos negociadores nas mesas.

Para desenvolver essa dimensão de educação, o Dieese adotou institucionalmente uma concepção pedagógica coerente com seus princípios, assentada no diálogo como base da troca de saberes nos espaços de aprendizado, na construção coletiva a partir das práticas e experiências das pessoas e grupos e na busca de uma abordagem que compreenda a diversidade de olhares, interesses e propósitos presentes na realidade. Uma prática educativa que busca fortalecer valores como liberdade, solidariedade e tolerância, entre outros.

\section{DÉCADA DE 90: A QUESTÃO DO EMPREGO TORNA-SE PRIORIDADE}

Ainda nos primeiros anos da década de 80, antevendo a necessidade de melhor compreensão do mercado de tra- 
balho, o Dieese, em conjunto com cientistas vindos da área acadêmica, iniciou um debate que resultou na estruturação de uma das mais importantes pesquisas sobre mercado de trabalho: a PED - Pesquisa de Emprego e Desemprego, realizada em parceria com a Fundação Seade, órgão da Secretaria de Economia e Planejamento do governo do Estado de São Paulo. Já a partir dos primeiros resultados, a PED confirmou que o mercado de trabalho brasileiro, dadas as suas particularidades, merecia enfoque diferenciado que captasse as diversas condições de atividade dos indivíduos, em particular as do desemprego.

A PED, inicialmente realizada na Região Metropolitana de São Paulo, expandiu-se para outras seis áreas metropolitanas e para o Distrito Federal, sendo atualmente executada regularmente em seis regiões (São Paulo, Porto Alegre, Belo Horizonte, Salvador, Recife e Distrito Federal).

Até meados da década de 90, a inflação e as políticas salariais prosseguiram no centro do debate. Entretanto, os desdobramentos da abertura econômica e da reestruturação produtiva em curso foram deslocando o eixo das relações de trabalho para o tema do emprego, em todas as suas dimensões.

Com a abertura econômica, uma nova linha de argumentação do governo e dos patrões começa a se desenhar. Em um primeiro momento, enquanto fracassavam as tentativas do governo Collor contra a inflação, manteve-se a alegação de que os reajustes salariais eram prejudiciais à economia. Adicionalmente consolidou-se o questionamento sobre os direitos dos trabalhadores, que, segundo governo e empresários, mantinham altos os custos do trabalho(!) e ameaçavam a competitividade dos produtos brasileiros no mercado internacional.

Neste período, reelaboraram-se os argumentos de que aumentos salariais levariam a aumentos da inflação e, aliados à manutenção dos direitos trabalhistas, à perda de competitividade dos produtos brasileiros, o que, conseqüentemente, resultaria no crescimento do desemprego. Assim, aumentos salariais e permanência de direitos seriam prejudiciais aos trabalhadores, inclusive no que se refere à manutenção ou à ampliação do emprego.

Ainda foi construída uma outra argumentação - em nível macroeconômico - que, em primeiro lugar, minimiza o problema do desemprego e, em segundo, atribui ao trabalhador a responsabilidade pela sua exclusão do mercado de trabalho. Nessa direção, partindo da premissa de que "não há desemprego", chega-se à conclusão de que o que falta é "qualidade dos postos de trabalho e da mão-de-obra".

Nos anos 90, como foi dito, a PED, que era realizada apenas em São Paulo, foi implantada nos mesmos moldes institucionais em outras regiões e tornou-se uma importante referência em diversas localidades do território nacional, contrapondo-se às estatísticas oficiais. Isso ocorre dado que a identificação das diversas formas que revestem o desemprego passa ao largo das estatísticas oficiais, com evidentes reflexos sobre as políticas públicas de emprego.

Curiosamente, repetindo a situação das décadas anteriores, o Dieese encontra-se em meio a uma guerra de números, só que desta vez relacionados ao desemprego. Nos anos 90, no debate em torno dos números do desemprego, o discurso do governo e dos cientistas aliados procurou desqualificar a pesquisa do Dieese e da Fundação Seade não mais pela ignorância dos trabalhadores na produção de conhecimento, posto que a consolidação do Dieese como órgão científico encurtou as margens para este tipo de crítica. A desqualificação agora enveredou pelo emaranhado técnico e, entre outros argumentos, tentou atingir a metodologia da Pesquisa de Emprego e Desemprego pela diferenciação significativa desta em relação às utilizadas internacionalmente. Em outras palavras, a crítica do governo é centrada exatamente no ponto que qualifica a PED: o desenvolvimento de uma metodologia adequada à heterogeneidade do mercado de trabalho brasileiro, que se distingue, radicalmente, do mercado de trabalho presente em países desenvolvidos.

No entanto, é fundamental frisar que, em sua construção, a PED contemplou os indicadores que permitem a comparação internacional, em particular a taxa de desemprego aberto (Dieese, 1996).

Foi também a PED que permitiu ao Dieese lançar-se a discussões que transcendem a situação dos trabalhadores organizados e remeter-se à defesa de interesses mais abrangentes, envolvendo, inclusive, as questões de políticas públicas.

\section{O PAPEL DE SINDICALISTAS E TÉCNICOS NA CONSTRUÇÃO DO DIEESE}

Uma das características marcantes do Dieese é resultante da relação entre sindicalistas e técnicos, o que imprime uma dinâmica singular à instituição e permite a interação entre conhecimento e ação.

Os sindicalistas presentes no Departamento são lideranças de carreira sindical, provenientes de setores hegemônicos e mobilizadores e representam um largo espectro de tendências partidárias. A eles cumpre o papel fundamental de dirigir a instituição, através da adminis- 
tração do conhecimento produzido pelos técnicos, estabelecendo as conexões entre as diversas áreas sindicais e coordenando o fluxo de informações.

Já os técnicos, de formação humanista e engajados politicamente, tendem a não participar da vida partidária e dedicar-se ao Dieese, dado que assessoram uma imensa gama de sindicatos das mais diversas matizes políticas. Seu papel é o de produzir conhecimento que deverá ser instrumentalizado e articular a produção técnica do departamento (Chaia, 1992).

Nesse processo, cabe ressaltar a importância do Dieese em traduzir as análises realizadas em linguagem acessível às lideranças sindicais. Assim, à preocupação de interpretação e análise da realidade pela perspectiva da classe trabalhadora, através da operacionalização do conhecimento acadêmico, os técnicos do Dieese agregam o desenvolvimento de técnicas para tornar assimilável a produção realizada.

\section{PRIMEIRA DÉCADA DO NOVO SÉCULO: PERSPECTIVAS}

As alterações ocorridas na economia brasileira nos anos 90 tiveram impacto significativo na atuação do Dieese. Fruto da luta pela democratização, inúmeros espaços institucionais foram conquistados pela representação dos trabalhadores. Paralelamente ao avanço institucional, as relações de trabalho e as negociações coletivas foram afetadas pela nova realidade econômica. Sinteticamente podese afirmar que as questões tradicionais predominantes no mundo do trabalho, até meados da década de 90 , tais como inflação e política salarial, passaram a conviver com novos temas, sobretudo aqueles relacionados ao emprego e ao desemprego.

Também a globalização impulsionou as transformações no mundo do trabalho, trazendo à superfície questões de gênero, trabalho infantil e raça, entre outras.

Para o Dieese, essa ampliação da agenda teve profundas implicações para o desafio de produzir conhecimento. Diferentemente do período anterior - da ditadura militar -, na democracia, e com uma agenda temática ampla e complexa, cresceram as dificuldades para assegurar a eficácia dessa produção na assessoria ao movimento sindical. Também vale lembrar que, nesse período, o potencial de conflito entre as diversas correntes do movimento sindical aumentou consideravelmente.

No âmbito das negociações coletivas, tem-se renovado a necessidade de conhecer com mais profundidade setores e empresas, já que as negociações sobre condições de traba- lho incorporaram a dimensão do emprego, o que exige uma nova estratégia que considere o conhecimento das lógicas das cadeias produtivas e das empresas num ambiente histórico de inacessibilidade às informações das empresas.

Ademais, a negociação no plano institucional conduz o Dieese como órgão de pesquisa e assessoria a uma nova etapa de produção técnica, ligada à formulação de propostas de políticas públicas e estratégias de desenvolvimento. Os planos da pesquisa e análise não são suficientes para responder plenamente às necessidades de atuação do movimento sindical. É necessário propor para poder "conversar" com todos os segmentos da sociedade, uma vez que as questões de emprego dizem respeito ao conjunto da sociedade e não apenas ao setor organizado.

Essa tensão na atuação do Dieese ainda está em curso. Dela resultará a nova forma de produção do conhecimento na entidade e também suas perspectivas de permanecer no cenário com a credibilidade que tem desfrutado no decorrer de sua história.

\section{NOTAS}

Colaboraram Vera Gebrin, Wilson Amorim e Clemente Lúcio. Agradeço aos dirigentes e técnicos, do passado e do presente, pela possibilidade de assinar esse artigo. Como é de praxe, os eximo de qualquer responsabilidade sobre a versão final.

1. A assembléia de fundação do Dieese ocorreu em 22 de dezembro de 1955.

\section{REFERÊNCIAS BIBLIOGRÁFICAS}

CHAIA, M.W. Intelectuais e sindicalistas: a experiência do Dieese (1955-1990). Ibitinga, Humanidades, 1992.

DIEESE. Estudos Sócio-Econômicos. Família assalariada: padrão e custo de vida. São Paulo, v.1, n.2, jan. 1974.

. Estudos Sócio-Econômicos. 10 anos de política salarial. 2.ed. São Paulo, v.1, n.3, ago. 1975.

"A controvérsia sobre as taxas de desemprego no Brasil". Boletim do Dieese. São Paulo, n.183, ano XV, jun. 1996.

EARP, F.S. "Um pouco além de Thomas Kuhn: da história do pensamento econômico à história da ciência econômica". Revista de Economia Política. São Paulo, Centro de Economia Política, v.16, n.1 (61), jan./mar.1996, p.57-69.

SIMONSEN, M.H. e CAMPOS, R. de O. A nova economia brasileira. Rio de Janeiro, J.Olympio, 1975 (Biblioteca do Exército).

Sérgio E.A. Mendonça: Economista. Diretor Técnico do Dieese (sergio@dieese.org.br). 